Journal of Engineering Sciences, Assiut University, Vol. 39, No. 4, pp.827-838, July 2011.

\title{
APPARENT VISCOSITY MIXING INDEX USING CFD COMPUTATIONS FOR NON-NEWTONIAN FLUIDS USING HELICAL RIBBON IMPELLER
}

\author{
A.A. Rsheed, Y.S. Fangary and N.A. Mahmoud \\ Mechanical power engineering dept. Faculty of engineering, Ain Shams University
}

(Received May 24, 2011 Accepted June 26, 2011)

\begin{abstract}
In the present study a mixing index was proposed in order to characterize mixing processes of non Newtonian fluids. The apparent viscosity in a mixing tank equipped with helical ribbon impeller was computed using a CFD package. The symmetry plane of the mixing tank was divided into sixteen zones where an average apparent dimensionless viscosity was calculated to each of these zones from which a mixing index was evaluated. The mixing index showed to increase with impeller rotational speed, impeller/tank diameter ratio and showed to be affected by the rheological parameters of the agitated fluid. The computed data of the mixing index were correlated as a function of impeller/tank diameter ratio, impeller rotational speed and rheological parameters. The proposed correlation deviated from computed data by a maximum deviation of $\pm 50 \%$.
\end{abstract}

\section{INTRODUCTION}

Mixing of fluids contributes a large extent in the processes including chemical industry. The fluid may be either Newtonian or non-Newtonian according to the process characteristics. Extensive works had been done to study and nearly reach a complete characterization of mixing of Newtonian fluids while comparably scarce work was carried out regarding non-Newtonian fluids.

The main parameters studied for characterization of mixing processes were the effect of impeller type, direction of impeller rotation, ratio of impeller diameter to tank diameter and impeller rotational speed on the mixing processes [1-3], also the effect of rheological properties and flow conditions on the mixing process was considered by [4-7].

Using numerical solution of the governing equations [8-12] carried out their work to find the velocity distribution in the mixing tank and tried to reach a solution for the power consumed and the quality of mixing in the tank.

Another approach was proposed by following the fluid particles inside the tank either visually [13] or by tracing radio active particle [14] and then by measuring the trajectory of the followed particle estimating the quality of mixing.

A mixing index was proposed [15] to asses mixing processes for Newtonian and non-Newtonian fluids based on velocity measurements from LDV. The main problem was that the data yielded same index for different processes indicating that the index was a function of impeller characteristics and not a function of fluid properties.

Therefore, from the previous survey it is found that there were no investigations that studied mixing performance of non-Newtonian fluids based on the fluid properties of such complex fluids. 
The present study discusses the performance of mixing of non-Newtonian fluids using a mixing index based on the apparent viscosity of the fluid at different regions in the mixing tank and then calculating an index that represents the mixing performance as a function of impeller/tank diameter ratio, impeller rotational speed and rheological properties of the fluid being mixed.

\section{MATHEMATICAL FORMULATION}

\section{Governing Equations}

The basic equations solved in a mixing calculation are those describing the flow of fluids, namely, conservation of mass, momentum and energy. Since mixing usually involves liquids, the fluid can be considered incompressible. The flow is governed by the simplified set of continuity and Navier-Stokes equations:

Continuity:

$\frac{\partial u_{i}}{\partial x_{i}}=0$

Momentum:

$\frac{\partial u_{i}}{\partial z}+\frac{\partial u_{i} u_{j}}{\partial x_{j}}=\frac{1}{\partial} \frac{\partial p}{\partial x_{i}}+v \frac{\partial^{2} u_{i}}{\partial x_{j}^{2}}$

Here $u_{i}$ is the velocity in the ith direction, $\rho$ is the density, $p$ is the pressure and $v$ is the kienematic viscosity of the fluid.

The previous equations are supplemented with constitutive equations in order to account for the non-Newtonian character of the fluid. The equations were solved assuming laminar flow conditions.

\section{REPRESENTATION OF THE IMPELLER}

The mixing system used in the present work is shown in Fig (1). The mixing vessel is a flat-bottomed cylindrical tank with a diameter $(\mathrm{T})=1 \mathrm{~m}$ and the fluid height in the tank (H) was equal to the tank diameter. Helical ribbon impellers with diameters (D) of $0.33,0.42,0.50$ and $0.60 \mathrm{~m}$ were centrally positioned for each run. The blade width of the impeller was $0.08 \mathrm{~m}$, blade thickness was $0.003 \mathrm{~m}$. The number of blades of the impeller were two blades. The off-bottom clearance ratio $(\mathrm{C} / \mathrm{T})$ was set to a value of 0.33 where $\mathrm{C}$ is the off-bottom clearance. The shaft was rotating with speeds from 100 rpm to $700 \mathrm{rpm}$.

In the present work, non-Newtonian liquid (Carboxymethyl cellulose (CMC)) is used and described by the power law model, $\tau=k\left(\frac{d u}{d y}\right)^{n}$, having density of $1000 \mathrm{~kg} /$ $\mathrm{m}^{3}$ where $\mathrm{k}$ and $\mathrm{n}$ are the rheological fluid parameters.

The multiple reference frames (MRF) model [16], was used in the simulations. A rotating frame is used for the region containing the rotating components while a stationary frame is used for regions that are stationary. In the rotating frame containing the impeller, the impeller is at rest. In the stationary frame containing the tank walls, the walls are at rest. 

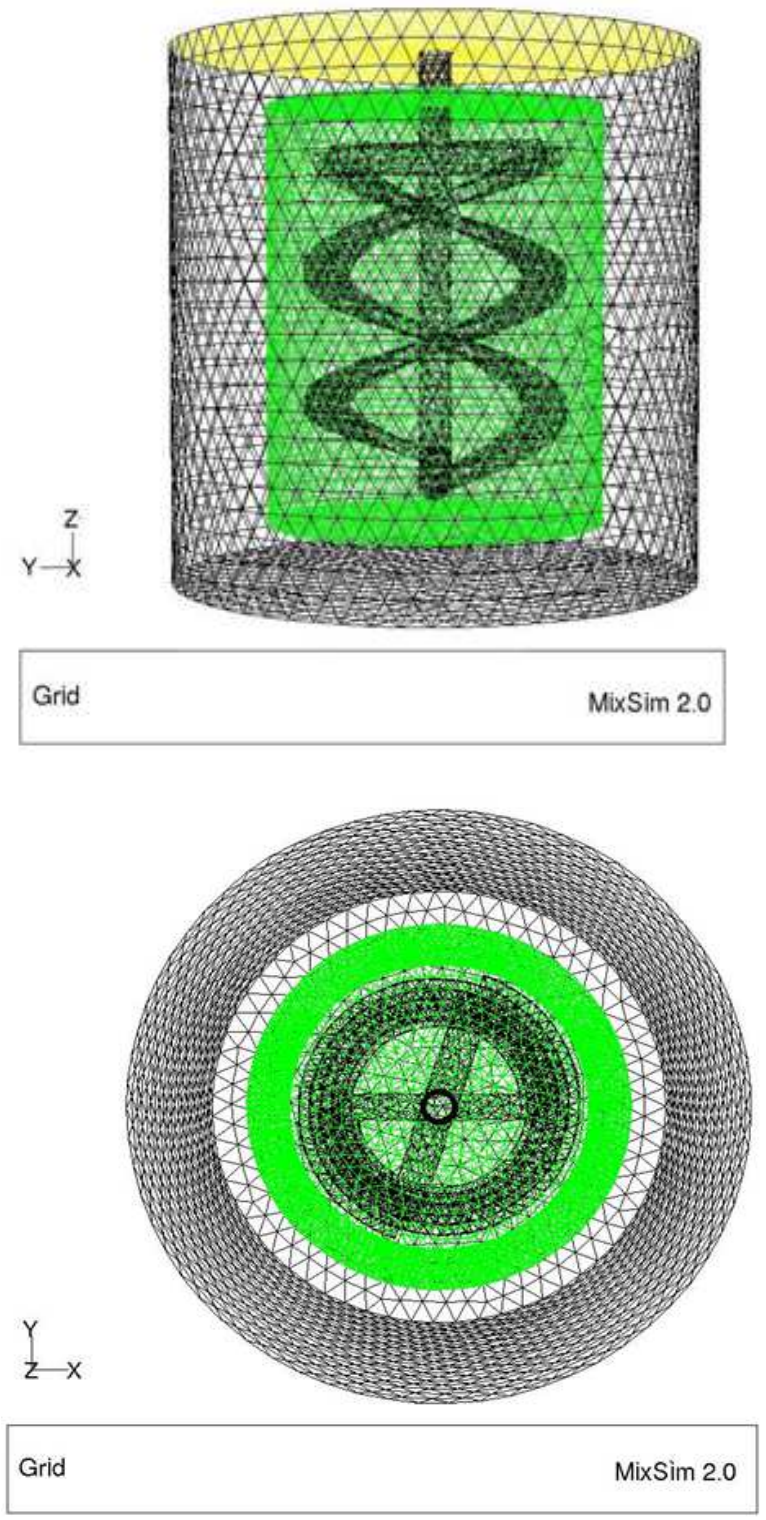

Fig. (1). Grid used for computations.

The steady-state 3D flow field generated by the helical ribbon impeller in the laminar flow regime was found by solving the conservation of mass and momentum equations. Also a pre-processor (Gambit 2.0, Fluent Inc.) built-in MIXSIM (software for the simulations) was used to discretize the flow domain with a tetrahedral mesh as shown in Fig. (1). In general, the density of cells in a computational grid needs to be fine enough to capture the flow details, so in order to capture the boundary layer flow details, a very refined mesh density was used in the entire tank wall and the rotating impeller. 


\section{SOLUTION OF THE GOVERNING EQUATIONS}

In a CFD solution, the flow domain is broken up into a number of contiguous non overlapping cells enveloping the whole domain and flow variables are sought at the centers of each of these cells. The governing equations are therefore discritized and linearized resulting in a set of coupled linear algebraic equations which are then solved using iterative schemes.

\section{The Mixing Index:}

CFD computations were carried out on a circular tank of diameter $1 \mathrm{~m}$ and the height of the fluid in the tank was equal to the tank diameter. The agitation of the fluid was maintained by a helical ribbon impeller. The diameter of the impeller was varied to cover $\mathrm{D} / \mathrm{T}$ ratios of $0.33,0.42,0.5$, and 0.6 . The rheological parameters of the fluid i.e. $\mathrm{k}$ and $\mathrm{n}$ values used are shown in table (1):

Table 1: Values of $k$ and $n$ used in the present work

\begin{tabular}{|c|c|}
\hline $\mathbf{k}$ & $\mathbf{N}$ \\
\hline 0.3 & 0.5 \\
\hline 0.3 & 0.65 \\
\hline 0.3 & 0.8 \\
\hline 0.5 & 0.5 \\
\hline 0.5 & 0.65 \\
\hline 0.5 & 0.8 \\
\hline
\end{tabular}

After computations were initiated and steady state was reached (indicated by errors in velocities computed to be $<10^{-4}$ ) calculations for the mixing index proposed as follows:

The symmetry plane showing the apparent viscosity distribution was divided into a grid of 16 cells, (I, II, III, ..... $\mathrm{m}=16$ ), as shown in Fig. (2):

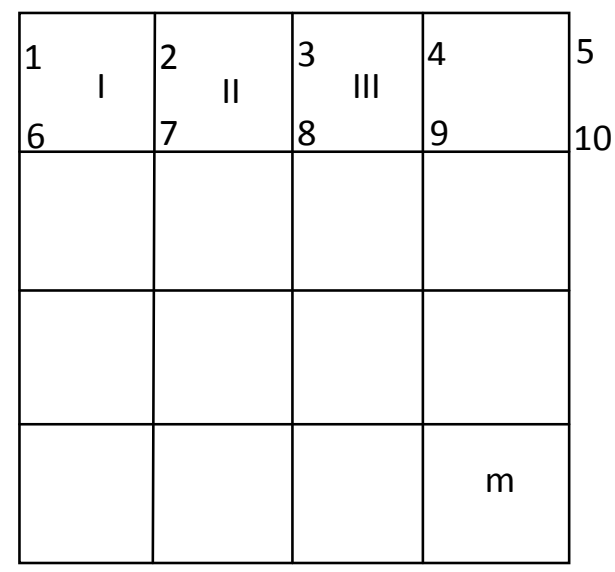

Fig.(2). Grid at the symmetry plane. 
The average dimensionless apparent viscosity $\left(\mu_{\mathrm{a}}\right)$ for cell I was calculated by:

$\mu_{a I}=\left[\frac{\left(\mu_{1}-\mu_{2}\right)^{2}+\left(\mu_{2}-\mu_{7}\right)^{2}+\left(\mu_{7}-\mu_{8}\right)^{2}+\left(\mu_{8}-\mu_{2}\right)^{2}}{\left(4\left(\mu_{\operatorname{man} I}-\mu_{\min I}\right)\right)^{2}}\right]$

Where $\mu_{\max }$ and $\mu_{\min }$ are the maximum and minimum values of the dimensionless apparent viscosity at the nodes of each cell. Therefore the mixing index for the whole grid was calculated from:

$\left.I=\left[\frac{\sum_{i=I}^{m 2} \mu_{a i}}{\left(16\left(\mu_{\text {grid max }}-\mu_{\text {grid min }}\right)\right.}\right)\right]^{n}$

Where $\mu_{\text {grid max }}$ and $\mu_{\text {grid min }}$ are the maximum and minimum values of $\mu$ for the whole grid, $\mathrm{n}$ is the flow behavior index of the fluid.

The number of cells was increased up to 128 cells and the result showed that only the values of the index changed but all the trends were the same. Therefore the grid in the present work has 16 cells, Since the values of the index do not by themselves have a physical interpretation for the mixing phenomenon, all the work was carried out using the 16 cell grid for simplicity purposes.

\section{Results and Discussions:}

In a mixing process the main duty of an impeller is to transfer the kienetic energy to the fluid in order to create a velocity field that is able to move the fluid in a manner that agitates the fluid in the mixing tank. The performance of agitation is dependent on the fluid properties (rheological properties in case of non-Newtonian fluids) and the design of the impeller. The helical ribbon impeller is the most popular in case of fluids with shear thinning properties or high viscosity Newtonian fluids. For this reason this study will focus on studying the performance of helical ribbon impeller agitating nonNewtonian fluid where the impeller diameter and fluid properties were varied.

Figure (3a) shows the velocity distribution in a mixing tank in which the fluid being agitated by an impeller of $\mathrm{D} / \mathrm{T}$ ratio $=0.33$, the rotating speed was $300 \mathrm{rpm}$ and the fluid having $k=0.3$ and $n=0.5$. From this figure it can be seen that high fluid velocities exist near the impeller along the tank while poor mixing zones exist away from impeller in other regions in the tank. The high upward circulation in the impeller region due to the rotation of the impeller is countered by a poor downward circulation in the region near the walls which indicates high dissipation of the kienetic energy in the zone between the impeller and the walls.

Figure (3b) shows the apparent viscosity distribution for the same conditions existing in Fig. (3a). Fig. (3b) reflects the findings from Fig.(3a) where it shows a lower viscosity region around the impeller and high viscosity region in the middle of the tank where a slightly lower viscosity region exists near the walls of the mixing tank which indicates that the fluid in the middle region between the impeller and the walls moves as a bulk in some manner. 


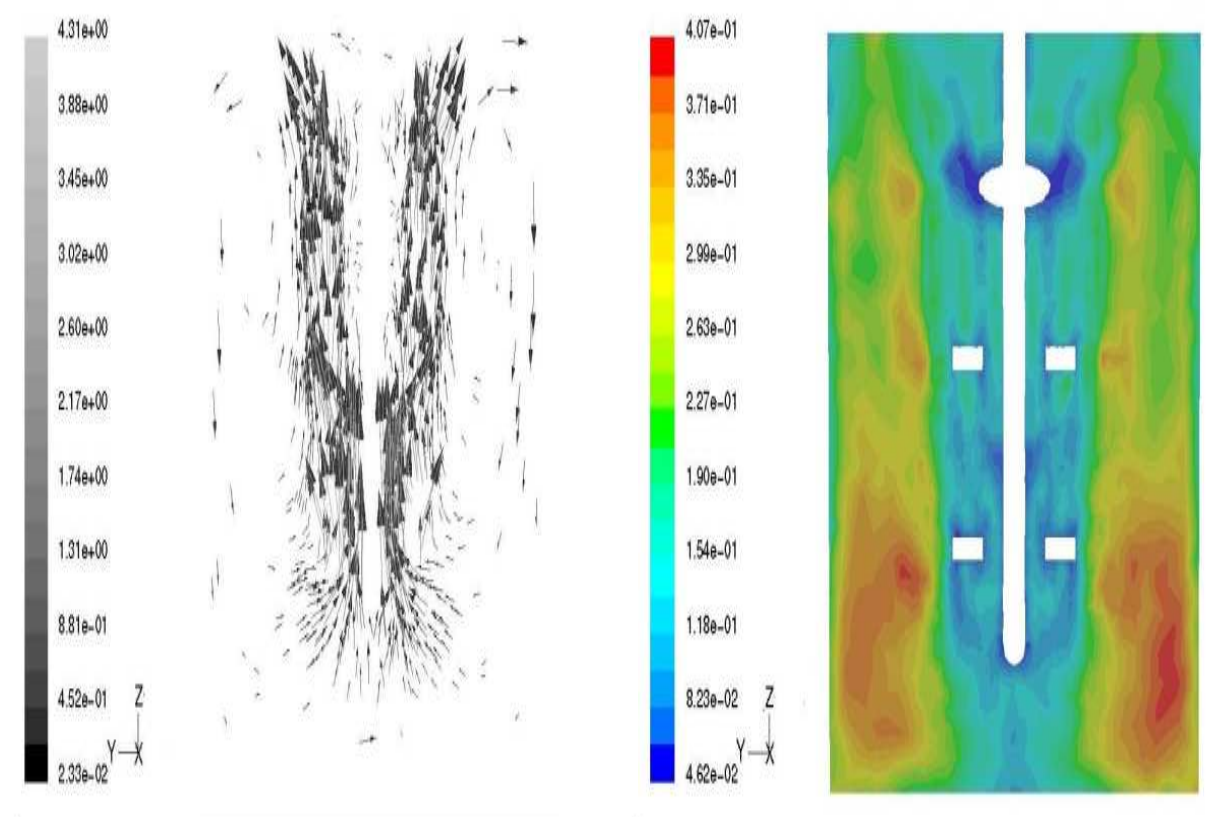

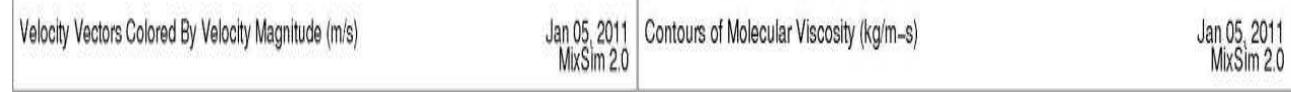

Fig(3). Distribution of velocity (a) and apparent viscosity (b) in the mixing tank, $\mathrm{D} / \mathrm{T}=$ $0.33, \mathrm{~N}=300 \mathrm{rpm}, \mathrm{k}=0.3$ and $\mathrm{n}=0.5$.

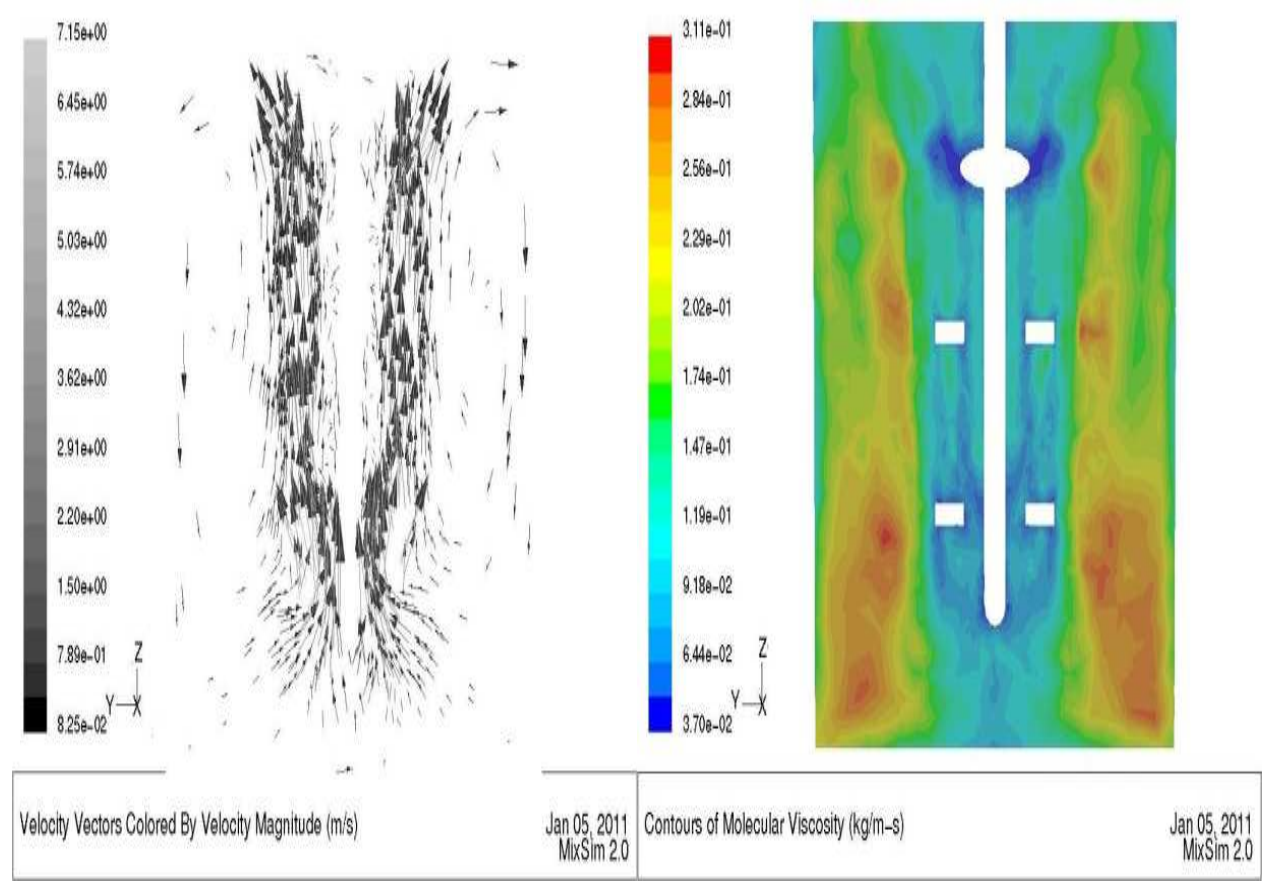

Fig(4). Distribution of velocity (a) and apparent viscosity (b) in the mixing tank, D/T = $0.33, \mathrm{~N}=500 \mathrm{rpm}, \mathrm{k}=0.3$ and $\mathrm{n}=0.5$. 
Figures (4a and 4b) show the velocity distribution and apparent viscosity distribution respectively for the same fluid properties and impeller diameter as in Fig. (3) but the rotational speed was increased to $500 \mathrm{rpm}$. Fig. (4) shows the same velocity and viscosity pattern as in Fig. (3) but the difference between the two figures is the velocity and viscosity values. Due to the increase of the rotational speed it is shown that the velocities in the moving parts are increased while the viscosity for the same regions was decreased.

Figures (5a and 5b) show the velocity distribution and apparent viscosity distribution respectively for the same fluid properties and rotational speed of Fig. (4) but the D/T was approximately doubled to have a value of 0.6. Fig. (5a) shows that the velocities in the mixing tank is well distributed in the region between the impeller and tank walls while a poor velocity distribution region exists at the core of the helical ribbon impeller. Examining Fig. (5a) shows that three circulation loops exist in the mixing tank, one at the bottom, another at the middle and the third at the top of the impeller. This indicates that the fluid is agitated and the fluid does not move as a bulk in this region.

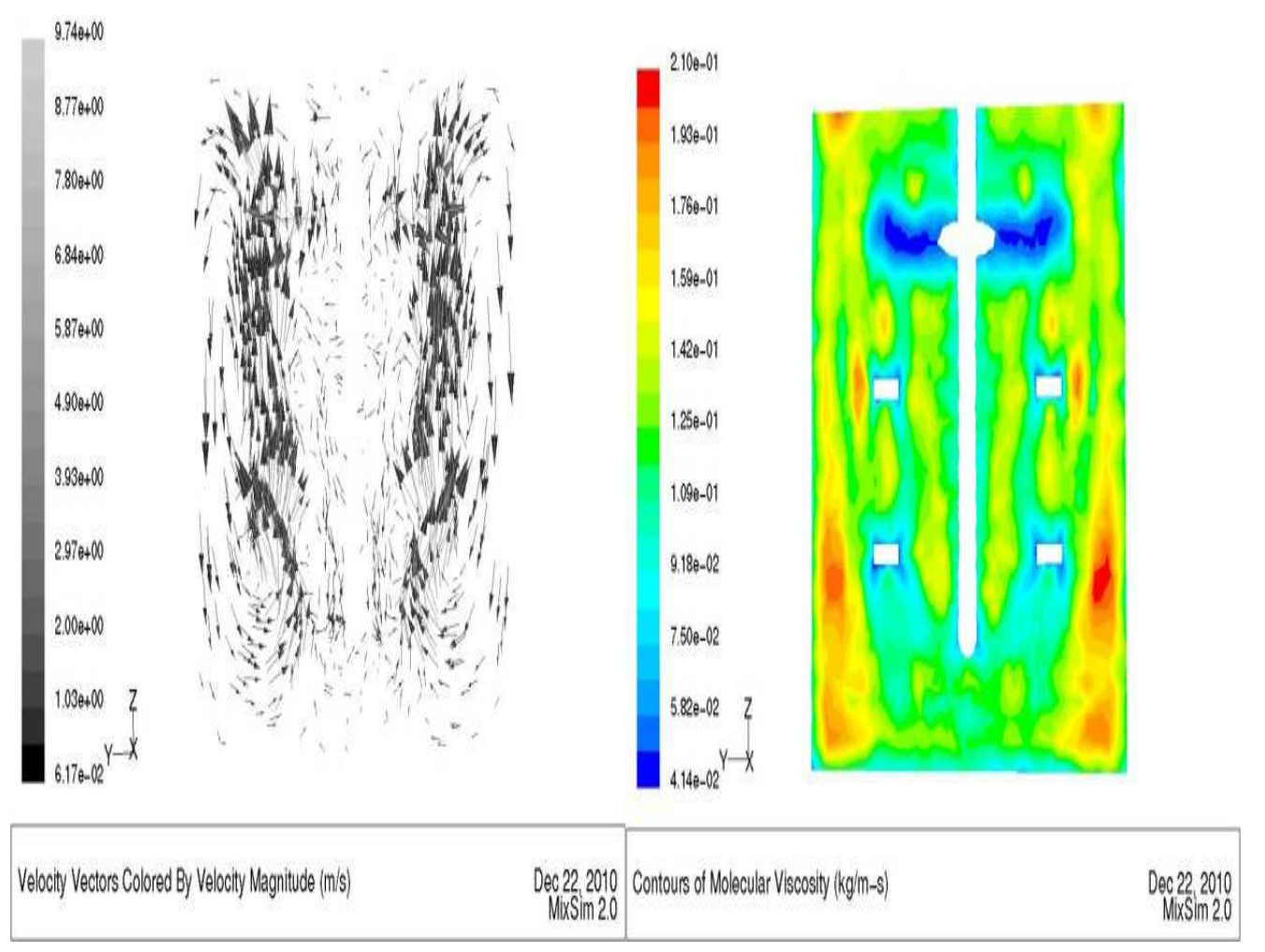

Fig(5). Distribution of velocity (a) and apparent viscosity (b) in the mixing tank, D/T = $0.6, \mathrm{~N}=500 \mathrm{rpm}, \mathrm{k}=0.3$ and $\mathrm{n}=0.5$.

Figure (5b) shows that the viscosity is lower at the bottom and at the top of the impeller. Examining Fig. (5a) indicates that the top and the bottom circulation is more efficient than the circulation in the middle region of the impeller. Also the viscosity 
distribution shows the existence of high viscosity region at the core of the impeller and at the corners of the mixing tank which indicates poor circulation in these regions.

The previous figures showed the effect of changing the impeller diameter and the rotational speed on the agitation of the fluid in the mixing tank. In order to show the effect of fluid properties on the agitation. The same geometry and rotational speed as those of Fig. (5) were used but the fluid properties were changed to $k=0.5$ and $n=$ 0.5 . The results of velocity and apparent viscosity distributions are shown respectively in Figs (6a) and (6b).

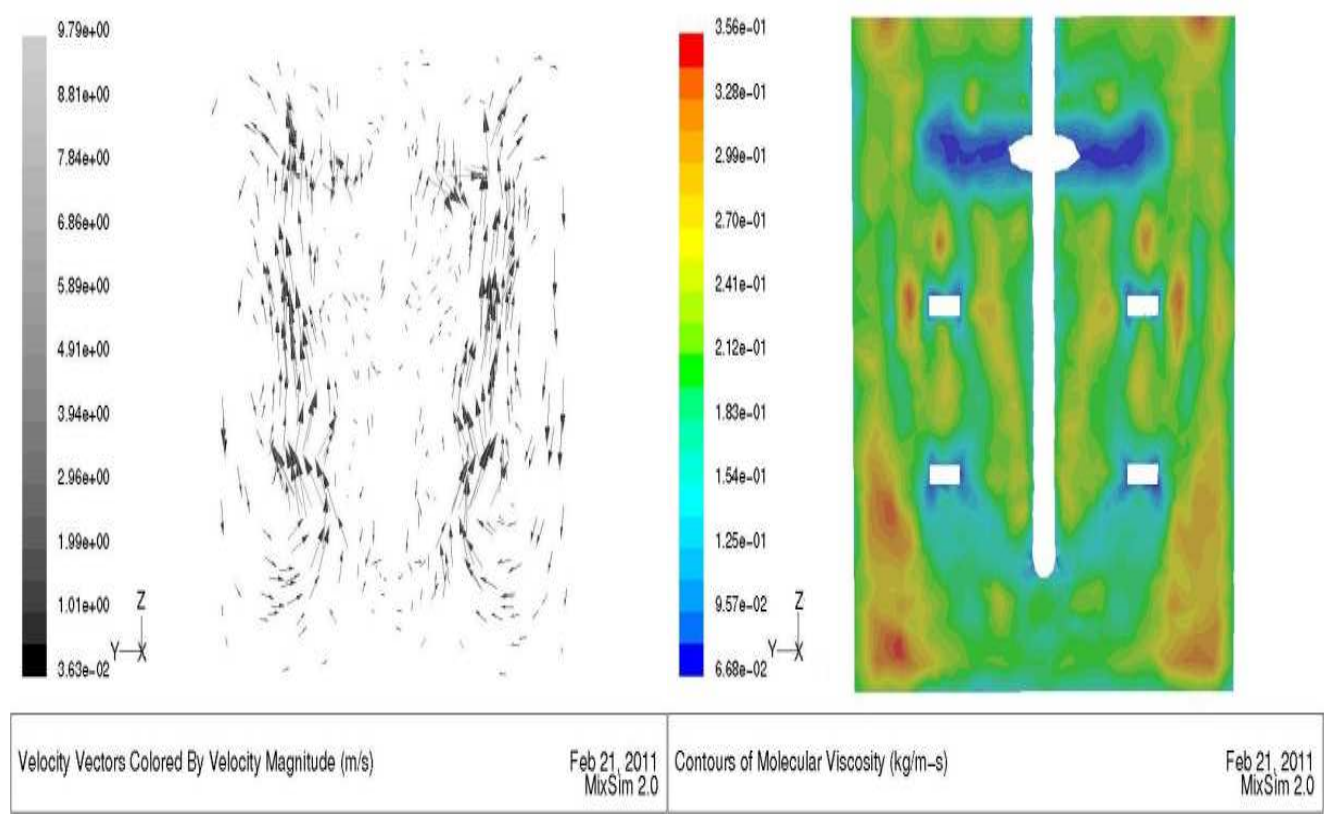

Fig(6). Distribution of velocity (a) and apparent viscosity (b) in the mixing tank, $\mathrm{D} / \mathrm{T}=$ $0.6, \mathrm{~N}=500 \mathrm{rpm}, \mathrm{k}=0.5$ and $\mathrm{n}=0.5$.

Figure (6a) shows the velocity distribution which has the same pattern as that in Fig. (5a) yet the values of velocities are lower in Fig.(6a) compared to that in Fig. (5a) and the poor mixing region in the core of the impeller is extended to include regions close to the impeller blades. The viscosity values in Fig.(6b) are nearly double the values in Fig.(5b) which explains the spread of poor velocity regions found in Fig. (6a).

From the previous it is found that increasing the rotational speed of the impeller increases the magnitude of the velocity but the pattern of agitation is the same. To extend the range of mixing in a mixing tank, this requires the increase of impeller diameter to export kienetic energy to wider regions in the mixing tank. Also it was found that increasing the apparent viscosity of the fluid by altering its rheological parameters reflects more strongly on the velocity distribution pattern rather than the viscosity distribution pattern.

The previous results showed qualitative judgment of agitation of a nonNewtonian fluid which can be accepted from a research point of view but not practically applicable. 
Therefore it is required to find a figure that reflects the performance of any agitation process by means of simple method of calculation. The method was explained earlier and the results will be shown in the following context.

Wide range of operating conditions were examined, several fluid rheological parameters were considered and different $\mathrm{D} / \mathrm{T}$ ratios were used to examine the effectiveness of using the proposed apparent viscosity index.

Figure (7) shows the mixing index calculated for a fluid of $\mathrm{k}=0.3$ and $\mathrm{n}=0.5$ at different impeller diameters and rotational speeds. The figure shows that the mixing index increases by increasing the rotational speed in a linear fashion. Also at the same rotational speed the mixing index is increased by increasing the impeller diameter which is in accordance with previous qualitative findings from Figs. (3-5).

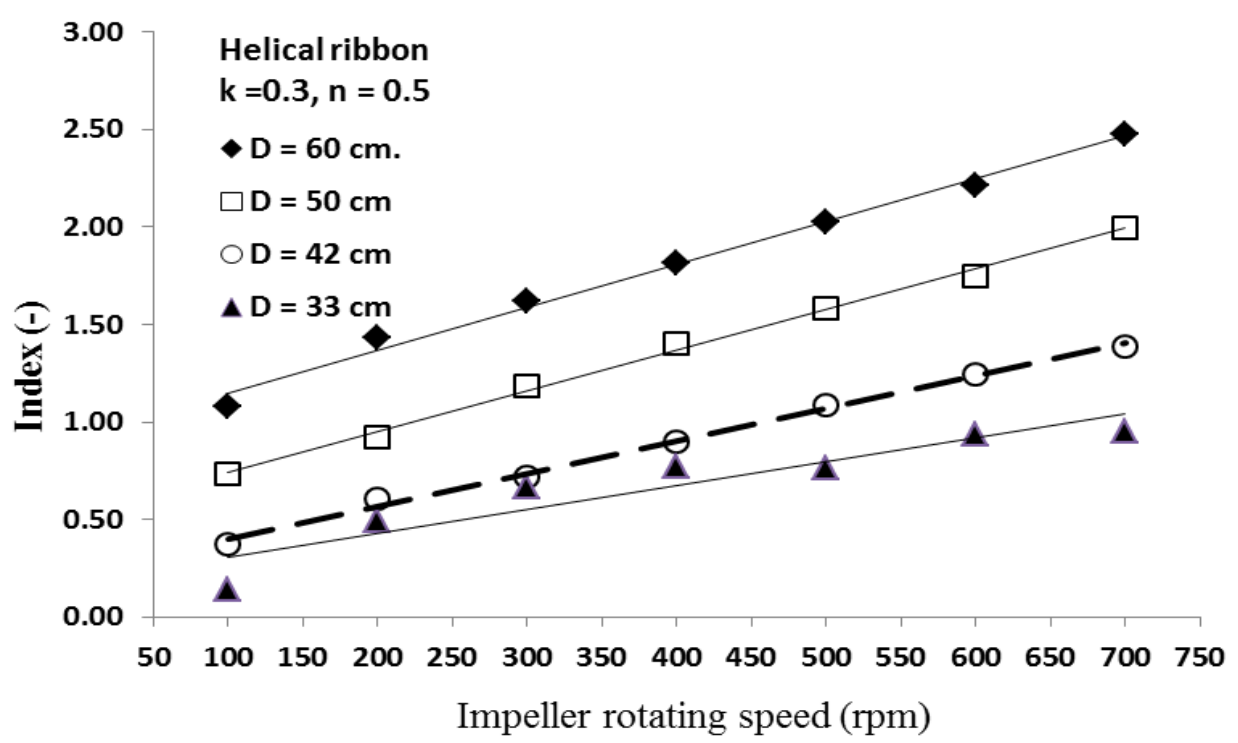

Fig(7). Mixing index at different rotating speeds and impeller diameters.

Figure (8) shows the mixing index for a fluid having $\mathrm{k}=0.5$ and $\mathrm{n}=0.5$ at different rotational speeds and impeller diameters. The same trend was found as in Fig. (7) but when comparing the values of the index it is clear that increasing the $\mathrm{k}$ value (which indicates the increase of the apparent viscosity for the same $n$ value) decreases the value of the mixing index which agrees with qualitative findings from Figs. $(5,6)$.

Furthermore an empirical correlation based on all data calculated to relate the mixing index with operating conditions was proposed in the form:

$I=\left[0.045(0.5 N)^{D / T}+0.4\right]^{\frac{n}{k}}$

It must be noted that the above correlation is applicable for the present design conditions as $(\mathrm{C} / \mathrm{T})$, no of blades, blade width and blade thickness.

This correlation was compared to the calculated indices and the results are shown in Fig.(9). From Fig. (9) it is shown that the correlation agrees with the calculated values of the mixing index with maximum deviation of $\pm 50 \%$. 


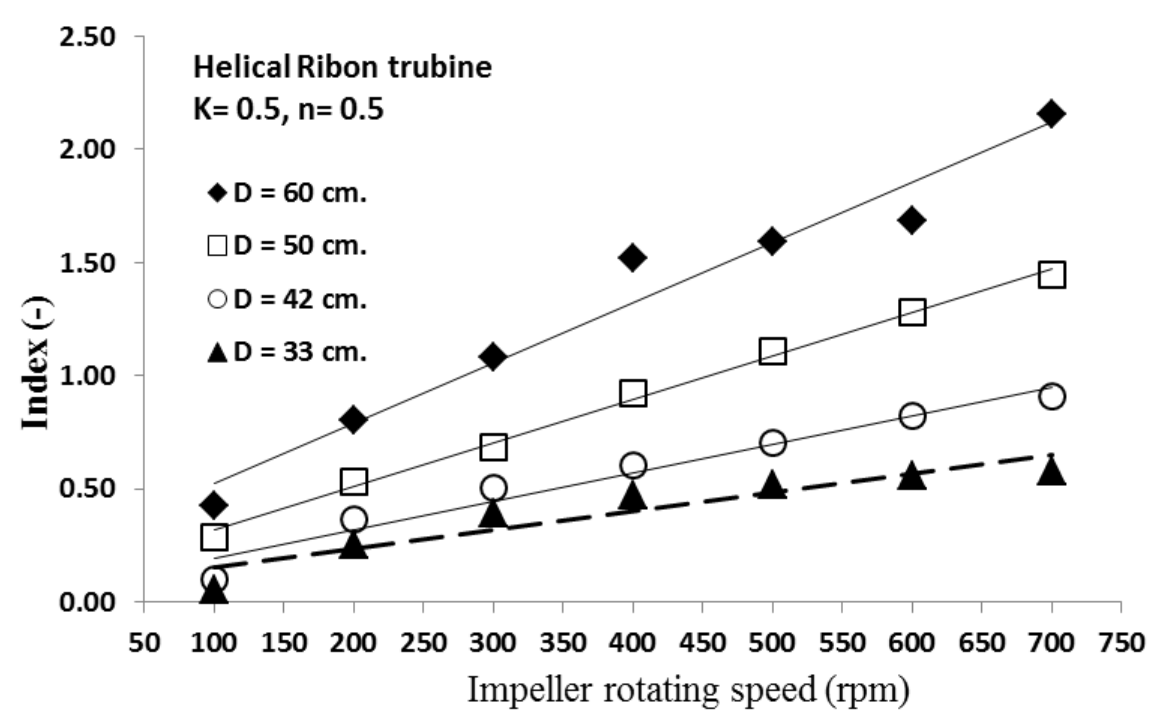

Fig(8). Mixing index at different rotating speeds and impeller diameters.

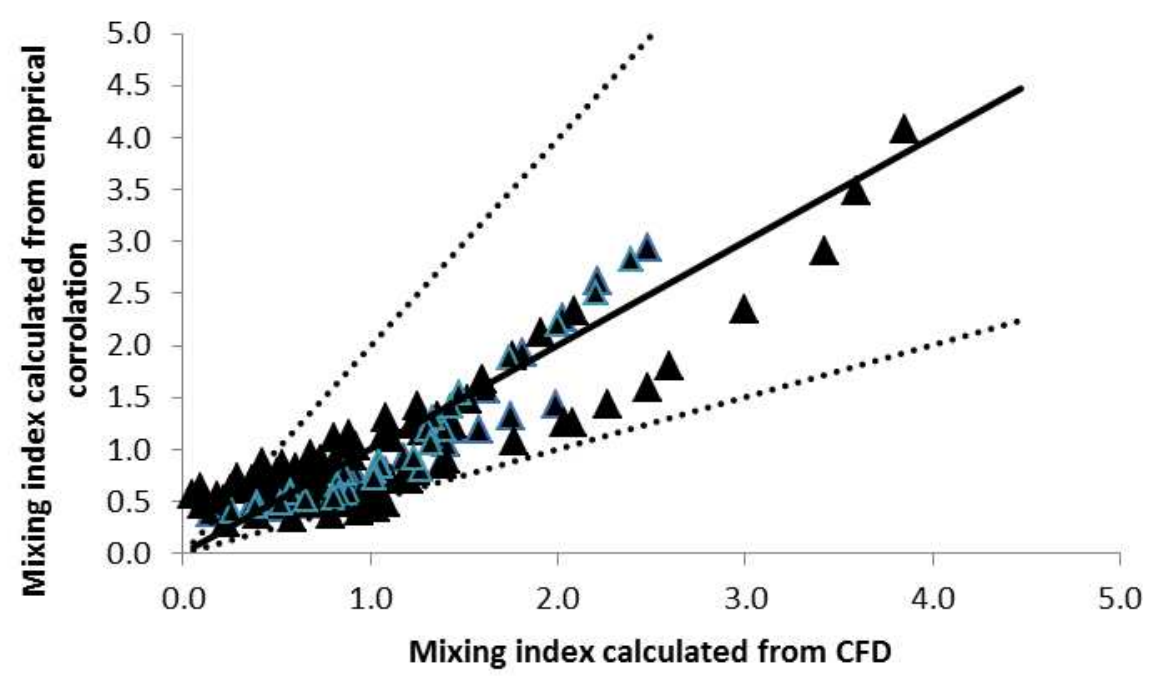

Fig. (9) Comparing computed values of the mixing index with calculated values.

\section{CONCLUSIONS}

Based on the present work it is found that it is possible to use CFD to obtain qualitative and quantitative judgment on mixing processes. The quantitative data in the form of mixing index is more useful when comparing between the mixing performance of different impeller speeds, different impeller to tank diameters or different fluid's rheological properties. Also it was possible to propose an empirical correlation in order to calculate the mixing index as a function of impeller to tank diameter ratio and impeller speed for design or comparison purposes, the correlation predicts the computed values of the mixing index with maximum deviation of $\pm 50 \%$. 


\section{NOMENCLATURE}

$\begin{array}{cll}\mathrm{C}: & \text { Off bottom clearance } & \lceil\mathrm{m}\rceil \\ \mathrm{D}: & \text { Impeller diameter } & \lceil\mathrm{m}\rceil \\ \mathrm{H}: & \text { Water height in the tank } & \lceil\mathrm{m}\rceil \\ \mathrm{I}: & \text { Mixing index } & \lceil-\rceil \\ \mathrm{k}: & \text { Consistency } & \left\lceil\mathrm{Pa} . \mathrm{s}^{\mathrm{n}}\right\rceil \\ \mathrm{N}: & \text { Impeller rotating speed } & \lceil\mathrm{rpm}\rceil \\ \mathrm{n}: & \text { Flow behavior index } & \lceil-\rceil \\ \mathrm{p}: & \text { Pressure } & \lceil\mathrm{Pa} . \mathrm{s}\rceil \\ \mathrm{t}: & \text { Time } & \lceil\mathrm{s}\rceil \\ \mathrm{T}: & \text { Tank diameter } & \lceil\mathrm{m}\rceil \\ \mathrm{u}: & \text { Velocity } & \lceil\mathrm{m} / \mathrm{s}\rceil \\ \mathrm{X}: & \text { Distance } & \lceil\mathrm{m}\rceil \\ \text { GREEK SYMBOLS } & \\ \mu & \text { Viscosity } & \lceil\mathrm{Pa} . \mathrm{s}\rceil \\ \mu_{\mathrm{a}} & \text { Average dimensionless apparent viscosity } & \lceil\mathrm{Pa} . \mathrm{s}\rceil \\ v & \text { Kienematic viscosity } & \left\lceil\mathrm{m}^{2} . \mathrm{s}^{-1}\right\rceil \\ \rho & \text { Density } & \left\lceil\mathrm{kg} . \mathrm{m}^{-3}\right\rceil\end{array}$

\section{REFERENCES}

1. P. Mavros, C. Xuereb and J. Bertrand. Determination of 3-D flow fields in agitated vessels by laser-doppler velocimetry: Effect of impeller type and liquid viscosity on liquid flow patterns. Trans IChemE. Vol. 74, Part A, pp 658-667, (1996).

2. T. Kumarsesan and J.B. Joshi. Effect of impeller design on the flow pattern and mixing in stirred tanks. Chemical engineering journal, 115, pp. 173-193, (2006).

3. R.K. Thakur, Ch. Vial, G. Djelveh and M. Labbafi. Mixing of complex fluids with flat bladed impellers: effect of impeller geometry and highly shear thinning behavior. Chemical engineering and processing, Vol. 43, 10, pp. 1211-1222, (2004).

4. J.-Y.Dieulot, G. Delaplace, R. Guerin, J. -P. Brienne and J. -C. Leuliet. Laminar mixing performances of a stirred tank equipped with helical ribbon agitator subjected to steady and unsteady rotational speed. Chemical engineering research and design. Vol. 80, 4, pp. 335-344, (2002).

5. M. Rice, J. Hall, G. Paadakis and M. Yianneskis. Investigation of laminar flow in a stirred vessel at low Reynolds numbers. Chemical engineering science, Vol. 61, 9, pp. 2762-2770, (2006).

6. P. Estelle and C. Lanas. Shear flow curve in mixing systems : A simplified approach. Chemical engineering science, Vol. 63, 24, pp. 5887-5890, (2008).

7. B. Triveni, B. Vishawnadham, T. Mahavi and S. Venkateshwar. Mixing studies of non-Newtonian fluids in an anchor agitated vessel. Chemical engineering research and design, Vol. 88, 7, pp. 809-818, (2010).

8. M. Kaminoyama, F. Saito and M. Kamiwano. Numerical analysis of three dimensional flow of a pseudoplastic liquid in a stirred vessel with turbine impeller. International chemical engineering. Vol. 30, No. 4, pp. 720-728, (1990). 
9. M. Kaminoyama, F. Saito and M. Kamiwano. Flow analogy of pseudoplastic liquid in geometrically similar stirred vessels based on numerical analysis. Journal of chemical engineering of Japan. Vol. 23, No. 2, pp. 214-221, (1990).

10. M. Kamiwano, F. Saito and M. Kaminoyama.Velocity distribution and apparent viscosity of a pseudoplastic liquid in a stirred vessel. International chemical engineering. Vol. 30, No. 2, pp. 274-280, (1990).

11. M. Kaminoyama, K. Arai and M. Kamiwano. Numerical analysis of power consumption and mixing time for a pseudoplastic liquid in geometrically similar stirred vessels with several kinds of plate-type impellers. Journal of chemical engineering of Japan. Vol. 27, No. 1, pp. 17-24, (1994).

12. F. Bertrand, P.A. Tanguy, E. Brito de la Fuente and P. Carreau. Numerical modeling of the mixing flow of second order fluids with helical ribbon impellers. Computer methods in applied mechanics and engineering, Vol. 180, 3-4, pp. 267-280, (1999).

13. J. Villermaux. Trajectory length distribution (TLD), a novel concept to characterize mixing in flow systems. Chemical engineering science, Vol. 51, No. 10, pp. 1939-1946, (1996).

14. Y.S. Fangary, M. Barigou, J.P.K. Seville and D.J. Parker. Fluid trajectories in a stirred vessel of non-Newtonian liquid using positron emission particle tracking. Chemical engineering science, Vol. 55, pp. 5969-5979, (2000).

15. P. Mavros and C. Baudou. Quantification of the performance of agitators in stirred vessels: Definition and use of an agitation index. Trans IChemE. Vol. 75. Part A. pp 737-744. (1997).

16. J.Y. Lou, R.I. Issa and A.D. Gosman. Prediction of impeller induced flows in mixing vessels using multiple frames of reference. Inst. Chem. Eng. Symp. Ser. 136, pp. 594-556, (1994).

\section{حساب معامل اللزوجة الظاهرية للخلط بواسطة نموذج حسابى للسوائل الغير نوتينية لمروحة خلط طنزونية}

تم فى هذا البحث اقتراح معامل لتقييم عمليات الخلط بالنسبة للسوائل غير نيوتونية. نم حساب هذا

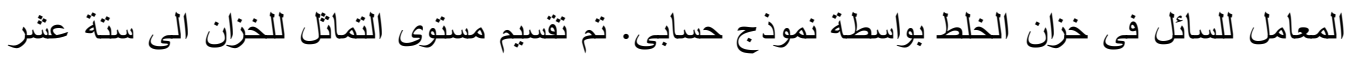
منطقة حيث تم حساب اللزوجة الظاهرية بطريقة لا بعدية لكل منطقة ومنها تم استتباط معامل الخلط

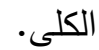

من الدراسة وجد أن معامل الخلط يرتفع مع زيادة سرعة مروحة الخلط وزيادة النسبة بين قطر المروحة لقطر الخزان. كما لوحظ أن هذا المعامل يتأثز بمعاملات السريان والتشكيل للسائل.

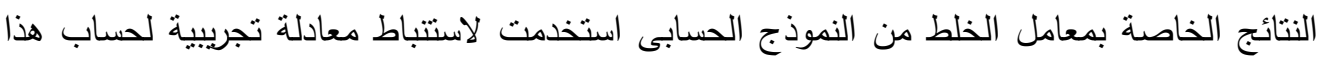
المعامل كدالة فى النسبة بين قطر المروحة وقطر الخزان، سرعة دوران المروحة، ومعامل السريان

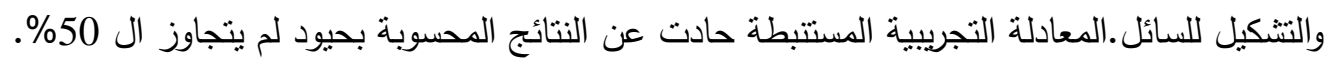

